\title{
Corrigendum
}

\section{Adolescent dietary patterns are associated with lifestyle and family psycho-social factors - CORRIGENDUM}

\author{
Gina L Ambrosini, Wendy H Oddy, Monique Robinson, Therese A O'Sullivan, \\ Beth P Hands, Nick H de Klerk, Sven R Silburn, Stephen R Zubrick, Garth E Kendall, \\ Fiona J Stanley and Lawrence J Beilin
}

First published online 29 July 2015

doi: 10.1017/S1368980008004618. Published by Cambridge University Press 23 January 2009

In describing the two dietary patterns identified in this manuscript, the authors reported that the variation in food intake explained by these dietary patterns amounted to $84 \%$ (paragraph 2 of Results, p4). This was the common variance shared by all foods entered into the dietary pattern analysis; whereas the total variance in food intakes explained by the patterns was $13 \%$ (Western dietary pattern) and $8.5 \%$ (Healthy dietary pattern), or $21.5 \%$ (this was not reported).

In paragraph 1 of the Discussion (p5) the authors incorrectly compared the total variance explained by dietary patterns reported in other studies with the common variance observed in our study. In fact, the total variance explained by dietary patterns in the study (21.5\%) is comparable to other studies (20-37\%).

This does not in any way affect the conclusions of this study regarding lifestyle and family psycho-social factors associated with adolescent dietary patterns.

\section{Reference}

Ambrosini GL, Oddy WH, Robinson M, O'Sullivan TA, Hands BP, de Klerk NH, Silburn SR, Zubrick SR, Kendall GE, Stanley FJ \& Beilin LJ (2009) Adolescent dietary patterns are associated with lifestyle and family psycho-social factors. Public Health Nutrition 12, $1807-1815$. 